\title{
Effect of chitosan and chitosan-nanoparticles on post harvest quality of banana fruits
}

\author{
Cita Lustriane $\cdot$ Fenny M. Dwivany $\cdot$ Veinardi Suendo $\cdot$ Muhammad Reza
}

Received: 22 January 2018 / Revised: 12 March 2018 / Accepted: 12 March 2018

(C) Korean Society for Plant Biotechnology

\begin{abstract}
In this study, we evaluated the effect of different concentrations of chitosan and chitosan nanoparticles as edible coating in extending shelf life and maintaining the quality of banana fruits (Musa acuminata AAA group). The fruit treated with $1.15 \%$ chitosan, $1.25 \%$ chitosan and chitosan nanoparticles then store at ambient temperature $\left(25 \pm 1^{\circ} \mathrm{C}\right)$. The shelf-life of banana, starch content, weight loss, pulp to peel ratio, total soluble solid, surface morpholgy of banana peel and sensory evaluation were analysed. Molecular analysis on the effect of chitosan was also conducted. Results showed that the application of chitosan nanoparticles and chitosan could extend shelf-life and maintain quality of banana fruits.
\end{abstract}

Keywords Chitosan, Edible Coating, Musa acuminata AAA group, Nanoparticles, Postharvest Quality

\section{Introduction}

Banana is one of the important fruit crops in the world

The authors' names and affiliations for the article "Effect of Chitosan and Chitosan-Nanoparticles on Post Harvest Quality of Banana Fruits" (Manuscript ID: JPB-18-001)

C. Lustriane $\cdot$ F.M. Dwivany $(\triangle)$

School of Life Sciences and Technology, Institut Teknologi

Bandung, Bandung, Indonesia

e-mail: fenny@sith.itb.ac.id

V. Suendo $\cdot$ M. Reza

Chemistry Department, Faculty of Mathematics and Natural

Sciences, Institut Teknologi Bandung, Indonesia

V. Suendo

Research Center for Nanosciences and Nanotechnology, Institut Teknologi Bandung, Indonesia

C. Lustriane

National Agency of Drug and Food Control Republic of Indonesia

F.M. Dwivany

Biosciences and Biotechnology Research Center, Institut Teknologi Bandung, Indonesia

Bali International Research Center for Banana, Indonesia trade. Banana is widely consumed because of a high nutritional content. The ripe banana is a fairly good source of carbohydrates, energy (100 cal per $100 \mathrm{~g}$ ), vitamin A, $B_{1}, B_{2}$ and $C$ (Cano et al. 1997). Banana is a typical climacteric fruit that has a different pattern of ethylene production compare to climacteric fruits in general. The ethylene production of banana shows a sharp increase and decrease at the beginning of the climacteric period (Burg and Burg 1962; Karikari et al. 1979). This physiological climacteric characteristic of banana fruit leads to a fast ripening process and a short shelf-life. Some technologies had been developed to extend shelf-life of banana using controlled atmosphere (CA) Storage (Ahmad et al. 2001), modified atmosphere (MA) packaging and low temperature storage (Kudachikar et al. 2011) etc., but the cost of these techniques are high.

An alternative method that can extend the shelf life of banana at a relatively low cost is edible coating. Edible coatings have received much attention because of its ability to prevent moisture loss, aroma loss, and inhibit the oxygen penetration to the plant tissue (Jianglian et al. 2013). In recent years, more attention has been paid to the study of biopolymer films such as polysaccharides to diminish crop losses and maintain the quality of fresh fruit for a longer period as an economical, simple, and biodegradable. Chitosan (CS) is one of promising biopolymer for edible coating because of its biocompatibility, biodegradability and non toxic (Jianglian et al. 2013). CS has been categorized as Generally recognize as safe (GRAS) by Food and Drug Administration (FDA) (Luo and Wang 2013). Chitosan is a polysaccharide obtained from deacetylation process of chitin, the second most abundant polysaccharide in nature after cellulose and can be found from many sources including exoskeletons of crustaceans, insects, mollusks and fungi (Jianglian et al. 2013; Luo and Wang 2013).

Nowadays, to enhance the effectiveness of edible coating performed by creating this coating in nano scale. The appli- 
cation of nanotechnology can improve the material properties including mechanical, thermal, barrier and physicochemical properties [Sorrentino et al, 2007]. Chitosan has hydroxyl and amino group on its backbones, so that chitosan can be easily modified into different form such as films, micro/ nano-particles, etc by various methods [Luo and Wang 2013]. According to our knowledge, there is no report on chitosan nanoparticles as an edible coating to maintain the postharvest quality of banana. Therefore, the objective of this research was to investigate the effect of chitosan nanoparticles and chitosan edible coatings on postharvest quality of banana.

\section{Materials and Methods}

Materials

Hands of mature green Cavendish banana (Musa acuminata AAA group) were purchased from PT. Sewu Segar Nusantara, Indonesia. Hands were sectioned into fingers and were visually selected for uniformity in size, color, and absence of physical damage and fungal infection. Chitosan food grade (High molecular weight and 85\% 89\% deacetylated) was purchased from Biotech Surindo, Indonesia. Sodium tripolyphosphate food grade was purchased from BrataChem, Indonesia. All chemicals used in the experiment were analytical grade.

\section{Preparation of chitosan coating}

Three different chitosan coatings $(1.15 \%$ chitosan, $1.25 \%$ chitosan and chitosan nanoparticles) were used as edible coating of banana. Chitosan nanoparticles $(\mathrm{CN})$ were obtained according to a modified method of Fan et al. 2012, based on the ionic gelation of chitosan with tripolyphosphate (TPP) anions. $0.25 \%(\mathrm{w} / \mathrm{w})$ chitosan was dissolved in $1 \%$ acetic acid and then agitated using stirrer until homogeneous. The $\mathrm{pH}$ of solution was adjusted to 4.7 by adding $1 \mathrm{~N} \mathrm{NaOH}$. Under magnetic stirring at room temperature, sodium TPP aqueous solution with concentration of 0.75 $\mathrm{mg} / \mathrm{mL}$ was gradually dropped into the chitosan solution. Chitosan (CS) were obtained according to a modified method of Jiang and $\mathrm{Li}$ 2001, chitosan with concentrations of $1.15 \%$ and $1.25 \%(\mathrm{w} / \mathrm{w})$ were prepared by dissolving the corresponding amount of chitosan in the solution containing $1 \% \mathrm{w} / \mathrm{w}$ acetic acid. The solution was agitated using stirrer until homogeneous. The $\mathrm{pH}$ of solution is adjusted to 5.5 by adding $1 \mathrm{~N} \mathrm{NaOH}$.

\section{Coating application}

Banana fruits were randomly selected and these banana fruits were grouped into 3 experimental sets and a control (uncoated) set. There were five replicates per treatment per evaluation date. The fruits were dipped into each chitosan coating solution for 2 minutes. Control and coated samples were stored at ambient temperature of $25 \pm 1^{\circ} \mathrm{C}$ for 15 days. The following analysis were carried out every two days to determine the effect of various chitosan coating solutions on the postharvest quality of banana.

\section{Characterization of chitosan nanoparticles}

Chitosan nanoparticles were characterized by following measurements. The particle size and particle size distribution of the chitosan nanoparticles were measured by Delsa Nano C Particle Analyzer, Beckman Coulter.

FT-IR spectra of Chitosan, TPP and Chitosan nanoparticles were taken with ALPHA FTIR Spectrometer. The FT-IR spectra were used to determine the existence of TPP and Chitosan in nanoparticles.

\section{Shelf-life}

The shelf life of banana fruits was assessed by conducting a visual observation. Shelf-life was calculated by counting the period between first day storage after treatment and end of edible life of banana fruits. In addition, banana maturity ratings for each fruit was evaluated by comparing the colour of each banana peel with a standard colour chart (Dadzie and Orchard 1997; Li et al. 1997). There are 7 point scale of banana maturity including $1=$ all green, $2=$ green with trace of yellow, $3=$ more green than yellow, $4=$ more yellow than green, $5=$ yellow with trace of green, $6=$ full yellow, $7=$ full yellow with brown spots.

\section{Conversion of starch into sugar}

Conversion of starch into sugar was assessed by using the starch iodine test. The mid-point of banana was cut transversely about $2 \sim 3 \mathrm{~cm}$ thick and then peel was separated from the pulp. The cut surface of the banana was dipped at a depth of $5 \mathrm{~mm}$ for 5 seconds in starch-iodine staining solution. The starch pattern of each fruit was assessed by comparing the stained cut surface with starch iodine staining chart for bananas which developed by Blankenship et al. 1993. Starch-iodine staining solution prepared by dissolving $1 \%$ potassium iodide (dissolve first in small amount of hot water) and $0,25 \%$ iodine in distilled water. 
Weight loss determination

Weight loss was measured based on the comparison of the weight of the coated sample at initial condition and each sampling day during the storage. The percentage of weight loss was calculated by calculating the differences between initial weight and final weight of bananas divided by initial weight.

Pulp to peel ratio

Pulp to peel ratio was measured by calculating pulp weight divided by peel weight. Pulp and peel were separated and weighed individually as described by Karmawan et al. 2009; Dwivany et al. 2016.

Total soluble solids (TSS)

The TSS content of banana fruit was determined by using a refractrometer (Atago) and performed as described by Pratiwi et al., 2015. Results were expressed as degree Brix ( ${ }^{\circ}$ Brix). Briefly, $15 \mathrm{~g}$ banana fruit pulp in each treatment was homogenized using a blender with $45 \mathrm{~mL}$ of distilled water. The mixture was centrifuged at $11000 \mathrm{rpm}$ for 5 min. A few drops of the filtrate were then placed on the prism of the refractometer before reading. The refractometer was calibrated with distilled water to give a $0{ }^{\circ}$ Brix reading at each measurements.

Scanning electron microscopy (SEM)

Square pieces $(1 \mathrm{~cm} \times 1 \mathrm{~cm})$ of $5 \mathrm{~mm}$ thickness of peel from the coated and uncoated (control) samples were cut from the mid-point of the fruit. Samples were freeze dried for about 7 hours. Then, the samples was analysed using SEM (JSM-6510LA).

Sensory evaluation

Sensory evaluation was conducted by 19 semi-trained panelists on treated bananas (six days of storage at $25 \pm 1^{\circ} \mathrm{C}$ ) and control. Samples of fruit pulp were presented in random order to panelists for sensory evaluations. Samples were rated on a seven-point hedonic scale $(1=$ extremely dislike, $7=$ extremely like) for taste, colour and overall acceptability.

RNA isolation and cDNA synthesis

RNA isolation carried out on coated bananas with the best
Table 1 Oligonucleotides used in PCR assay (Karmawan et al. 2009)

\begin{tabular}{cc}
\hline Primer & Sequence $\left(5^{\prime}-3^{\prime}\right)$ \\
\hline ACS1 F & CCGAGACTGGATGAAGAAGAA \\
ACS1 R & GTCTGGGTCAAATCTGGCTC \\
ACO F & CGAGATGCTTGCGAGAAATGG \\
ACO R & TGCAGCAAATTCCTTCATCGC \\
\hline
\end{tabular}

delaying result and uncoated bananas. RNA was isolated using Corderio's method (Corderio et al. 2008) from banana pulp. The isolated RNA was used as a template for cDNA synthesis. cDNA was prepared using an iScript ${ }^{\mathrm{TM}}$ cDNA Synthesis from BioRad.

Expression analysis of $M A-A C S 1$ and $M A-A C O$

Total cDNA from coated and uncoated banana were used for qualitative expression analysis for MA-ACS1 and MA-ACO gene by PCR method using ACS1 F/R and ACO F/R primer pairs designed by Karmawan et al., 2009 (Table 1). PCR consisted of 35 cycles of $94^{\circ} \mathrm{C}$ for $30 \mathrm{sec}, 48,5^{\circ} \mathrm{C}$ for $30 \mathrm{sec}$, and $72^{\circ} \mathrm{C}$ for $30 \mathrm{sec}$. The PCR products were then analyzed with gel electrophoresis. Gel electrophoresis images were captured with a digital camera (CanonTM IXUS 250HS). Gene expression was analyzed by measuring band intensities using ImageJ software.

Statistical analysis

Analysis of variance (ANOVA) was used to measure the treatment effect using SPSS software and followed by the Duncan's multiple comparisons test. Differences were considered to be significant when the p-values $\leq 0.05$.

\section{Results and Discussion}

Characterization of chitosan nanoparticles

In this study, $\mathrm{CN}$ were prepared by the ionic gelation method. The ionic gelation method involves a complexation between a polyelectrolyte and an oppositely charged polyelectrolyte. As a cationic polysaccharide, chitosan forms complex compounds with multivalent anions such as TPP. TPP is mostly used as an ion cross-linking agent because of its non toxic property (Fan et al. 2012; Moura et al. 2009; Gan et al. 2005). In this study, the particle size of $\mathrm{CN}$ was $121.2 \mathrm{~nm}$. The particle size distribution is reported 
as a polydispersity index (PDI). In this study the PDI was 0.395 . This indicated that $\mathrm{CN}$ is fairly homogeneous, since the PDI values was less than 0.5 (Avadi et al. 2010). Factors that can influence the formation of nanoparticles chitosan including chemical and property of chitosan. In this study, concentration and deacetylation degree of chitosan were $0,25 \%$ and $85 \% \sim 89 \%$. The particle size of nanoparticles will increase above this concentration as reported in previous study, the particle size of nano-chitosan at a concentration of $0.3 \%$ chitosan was $221 \mathrm{~nm}$ (Moura et al. 2009). In another study reported that the size of nanoparticles chitosan were significantly influenced by the concentration of chitosan (Fan et al. 2012; Gan et al. 2005). This is due to the intermolecular distance decreases as chitosan concentration increases, thus leading to a decrease cross-linking density between chitosan and TPP while an increase intermolecular cross-linking between chitosan molecules (Fan et al. 2012; Moura et al. 2009). This phenomenon, resulting in forming agregates so that the particle size increases. Deacetylation degree of chitosan could also affect the particle size. High deacetylation degree could form a fairly good nanoparticles because of its large positive charge density makes chitosan molecules have a large number of potential cross-linking sites (Fan et al. 2012; Mao et al. 2010). Furthermore, $\mathrm{CN}$ is also influenced by the $\mathrm{pH}$ of the solution. The amine groups of the chitosan are protonated in an acidic medium, resulting a high charge density of CS which is most important for the optimum interaction and polyionic complex formation (Gan et al. 2005). In this study, $\mathrm{pH}$ of chitosan solution was 4.7. It is in accordance with a previous reports on the effect of $\mathrm{pH}$ on the particle size of nanoparticles chitosan, where it was found that it could not produce nanoparticle when the $\mathrm{pH}$ below 4.5, while the chitosan was less protoned when the $\mathrm{pH}$ above 5.2, it caused electrostatic repulsion between the particles decreased so that the solution was easier to form microparticle (Fan et al. 2012; Gan et al. 2005; Jonassen et al. 2012).

\section{FTIR analysis}

FTIR spectra of $\mathrm{CN}$ and $\mathrm{CS}$ are shown in Figure 1. The peak at $3447 \mathrm{~cm}^{-1}$ is attributed to $-\mathrm{NH}_{2}$ and $-\mathrm{OH}$ groups stretching vibration. This peak is sharper in the $\mathrm{CN}$ indicating that the hydrogen bonding is enhanced. The peaks at $1657 \mathrm{~cm}^{-1}$ and $1598 \mathrm{~cm}^{-1}$ are attributed to the $\mathrm{CONH}_{2}$ and $\mathrm{NH}_{2}$ groups, respectively. These peaks shift hypsochromically to 1639 and $1557 \mathrm{~cm}^{-1}$ in the FTIR spectra of $\mathrm{CN}$ which caused by the interaction between $\mathrm{NH}_{3}{ }^{+}$ groups of chitosan and phosphate groups of TPP. This

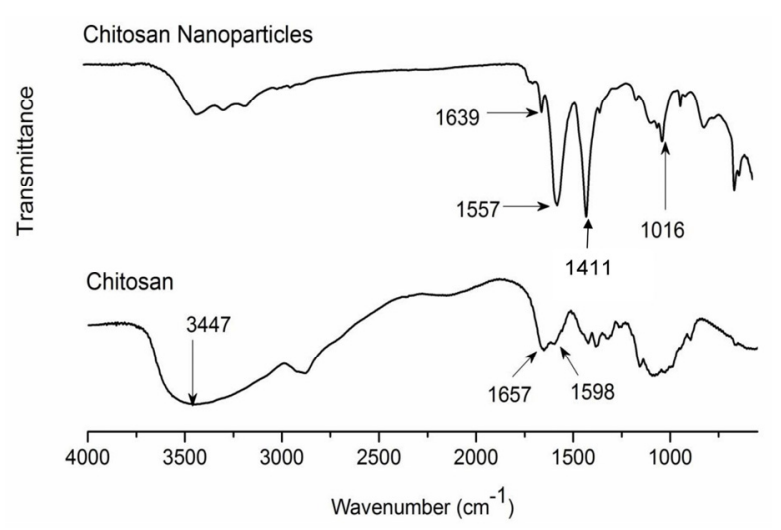

Fig. 1 FTIR spectra of Chitosan nanoparticles and Chitosan

interaction is also supported by the decrease of amide band I $\left(1639 \mathrm{~cm}^{-1}\right)$ intensity in $\mathrm{CN}$ compared to CS. The other significant band for $\mathrm{CN}$ was observed at $1411 \mathrm{~cm}^{-1}$ owing to $-\mathrm{CH}_{2}$ wagging. Furthermore, the peak at 1016 $\mathrm{cm}^{-1}$ which appears in the FTIR spectra of $\mathrm{CN}$ shows characteristic of $\mathrm{P}=\mathrm{O}$ stretching vibration from phosphate groups. Similar results of formation of chitosan nanoparticles treated TPP were reported in previous study (Qi et al. 2004; Bhumkar and Pokharkar 2006; Sarkar et al. 2013).

\section{Shelf-life}

The effect of various chitosan coatings on the shelf-life of banana are shown in Figure 2. Shelf-life associated with the period of banana to maintain the quality from a start of ripening until end of edible life of fruit.

As clearly observed in Figure 2, uncoated banana (control) had different stage of ripening compared to coated banana. On day 3, uncoated (control) banana was on stage 6 (full yellow), while coated banana was on stage 4 (more yellow than green). Banana treated with $\mathrm{CN} ; 1.15 \% \mathrm{CS} ; 1.25 \%$ CS showed a slower deterioration compared to uncoated banana. On day 9, uncoated banana was not edible because of excessive softness and started to decay while banana treated with $\mathrm{CN}$ was still edible. $1.15 \% \mathrm{CS}$ and $1.25 \% \mathrm{CS}$ could retard the decay and maintain the quality of banana until day 11 of storage. This results indicated that coating banana with chitosan $\mathrm{CN}, 1.15 \% \mathrm{CS}$ and $1.25 \% \mathrm{CS}$ can extend the shelf-life of Banana. Extending the shelf-life of fruits as a result of coating with $\mathrm{CN}$ and CS had also been reported in strawberry (Eshghi et al. 2014), litchi (Dong et al. 2004), longan (Jiang and Li 2001), mango (Chien et al. 2007).

The shelf life of banana coated with $1.15 \% \mathrm{CS}$ and $1.25 \%$ CS were longer than banana coated with $\mathrm{CN}$. This may be due to thickness of coating and it can be seen from 


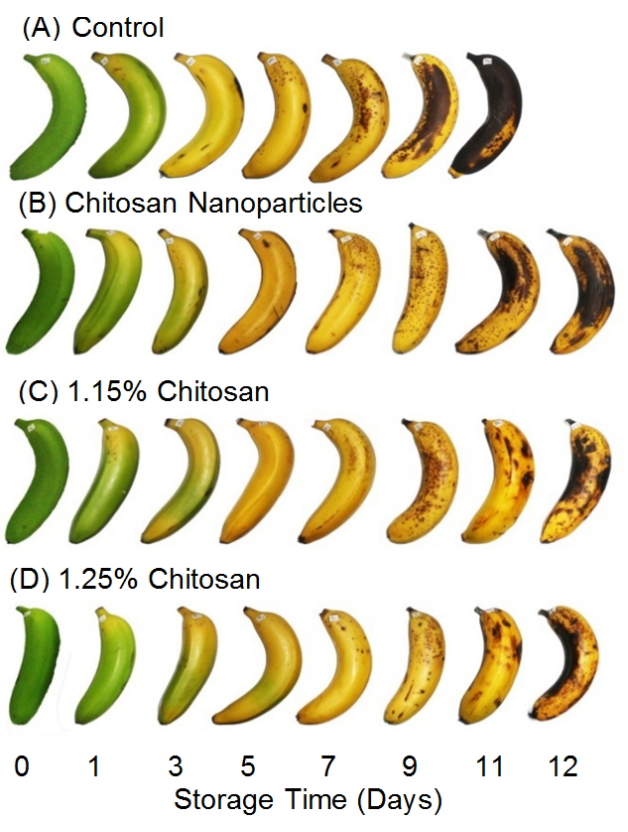

Fig. 2 Photographs of the changes in ripening stages of uncoated and coated banana fruits during storage at $25 \pm 1^{\circ} \mathrm{C}$

the SEM analysis of peel surface, the surface of $1.15 \%$ CS and $1.25 \%$ CS coated banana were completely covered (Fig. 6). Chitosan could be a fairly good barrier and the surface of banana and reduce the supply of oxygen (Maqbool et al. 2011). The low level of $\mathrm{O}_{2}$ and high level of $\mathrm{CO}_{2}$ can inhibit degradation of chlorophyll in banana peel (Sorrentino et al. 2007). Furthermore, the low level of $\mathrm{O}_{2}$ and high level of $\mathrm{CO}_{2}$ can inhibit the production of ethylene so that the ripening are delayed (Sorrentino et al. 2007). According to the our preliminary study, the $1,5 \%$ chitosan concentration lead banana to ripe improperly (data not shown). Thickness of chitosan coating may resulted in lack of gas diffusion (Park et al. 1993). This condition can generate heat and anaerobic condition which lead banana to produce ethanol (Ke and Kader 1989).

Conversion of starch into sugar

The effect of various chitosan coatings on starch content of pulp bananas are shown in Figure 3. In this study, starch content of banana pulp started to decrease on day 3. By comparing the starch pattern of each fruit with starch iodine staining chart for bananas which developed by Blankenship et al. 1993, starch content of pulp banana coated with $1.15 \%$ CS and $1.25 \%$ CS decreased about $5 \%$, while starch content of uncoated banana and banana coated with $\mathrm{CN}$ decreased rapidly about $65 \%$ on day 3 . All treated bananas were ripe by day 5 and it is difficult to compare fruit ripening stage by iodine test. The control has already

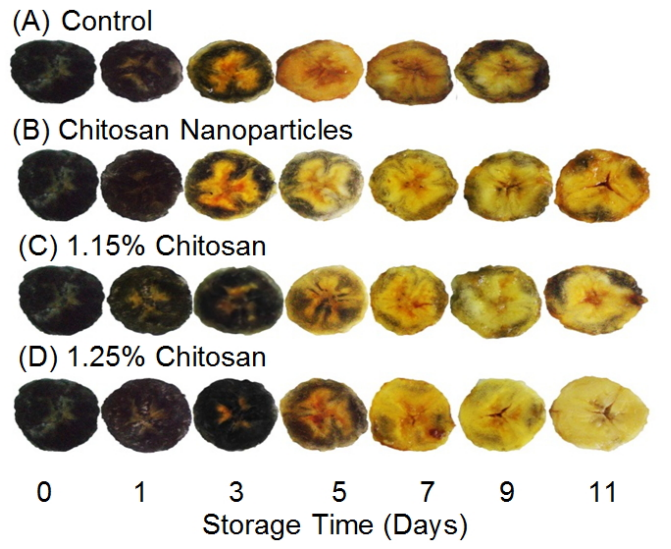

Fig. 3 The changes of starch pattern of coated and uncoated banana pulp

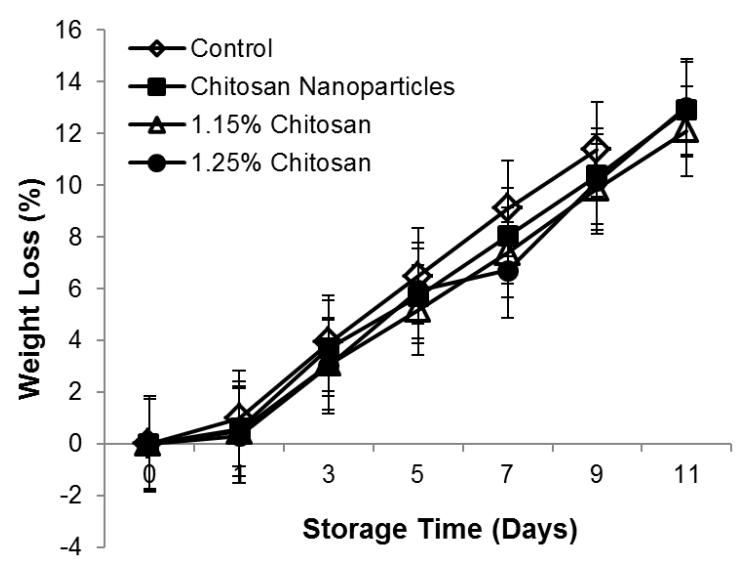

Fig. 4 Effect of Various Chitosan Coating Solutions on Weight Loss of Banana Fruits During Storage at $25 \pm 1{ }^{\circ} \mathrm{C}$ for 11 days

deteriorate at day 11 therefore iodine test was not performed. This results indicated that coating with CS inhibit conversion of starch to sugar due to the ability of this coating as a barrier. The conversion of starch into sugar is influenced by level of $\mathrm{O}_{2}$ and $\mathrm{CO}_{2}$. Low level of $\mathrm{O}_{2}$ and high level of $\mathrm{CO}_{2}$ can inhibit the activities of enzymes involved in hydrolysis of starch (Maqbool et al. 2011). Similar results of changes in weight loss of fruit coated with chitosan were reported in previous study (Eshghi et al. 2014; Dong et al. 2004; Jiang and Li 2001; Chien et al. 2007; Chien et al. 2013).

\section{Weight loss determination}

The effect of various chitosan coatings on weight loss are shown in Figure 4. In general, percentage of weight loss increased during ripening process. The treated banana with $\mathrm{CN}, 1.15 \% \mathrm{CS}, 1.25 \% \mathrm{CS}$ had significant $(\mathrm{P} \leq 0.05)$ effect on percentage of weight loss as compared to uncoated banana. As clearly observed in Figure 4, the weight loss 


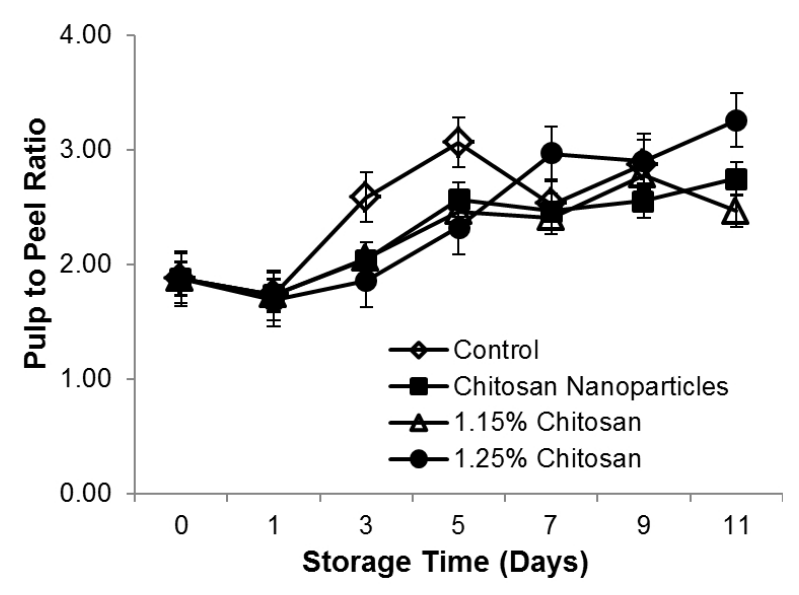

Fig. 5 Effect of Various Chitosan Coating Solutions on Pulp to Peel of Banana Fruits During Storage at $25 \pm 1^{\circ} \mathrm{C}$ for 11 days

of coated banana lower than uncoated banana (control). This results indicated that CN, $1.15 \%$ CS and $1.25 \%$ CS provided a good barrier to reduce water loss. The main factor that caused weight loss on fruit is water losses due to respiration process (Eshghi et al. 2014). In addition, the loss of a carbon atom from fruit during each cycle of respiration process may also cause weight loss (Chien et al. 2007).

\section{Pulp to peel ratio}

The effect of various chitosan coatings on pulp to peel ratio of bananas are shown in Figure 5. The treated banana with $\mathrm{CN}, 1.15 \% \mathrm{CS}$ and $1.25 \% \mathrm{CN}$ had significant $(\mathrm{P} \leq$ 0.05 ) effect on percentage of pulp to peel ratio as compared to uncoated banana. As clearly observed in Figure 5, the pulp to peel ratio of uncoated banana (control) increased rapidly on day 3. This could be due to the osmotic pressure. During ripening process, there is a rapid change of starch into sugar in banana pulp and leading to the change in osmotic pressure (Dadzie and Orchard 1997). The pulp to peel ratio of samples treated with $\mathrm{CN}, 1.15 \% \mathrm{CS}$ and $1.25 \%$ CS were lower compared to untreated samples. This indicated that chitosan coatings can inhibit metabollic process during ripening. Our results are similar to those reported by Pratiwi et al. 2015. They reported that the pulp to peel ratio of banana coated with chitosan was lower than uncoated banana.

Total soluble solids (TSS)

The effect of various chitosan coatings on TSS are shown in Figure 6. The uncoated (Control) banana had no significant $(\mathrm{P} \leq 0.05)$ effect on TSS as compared to coated

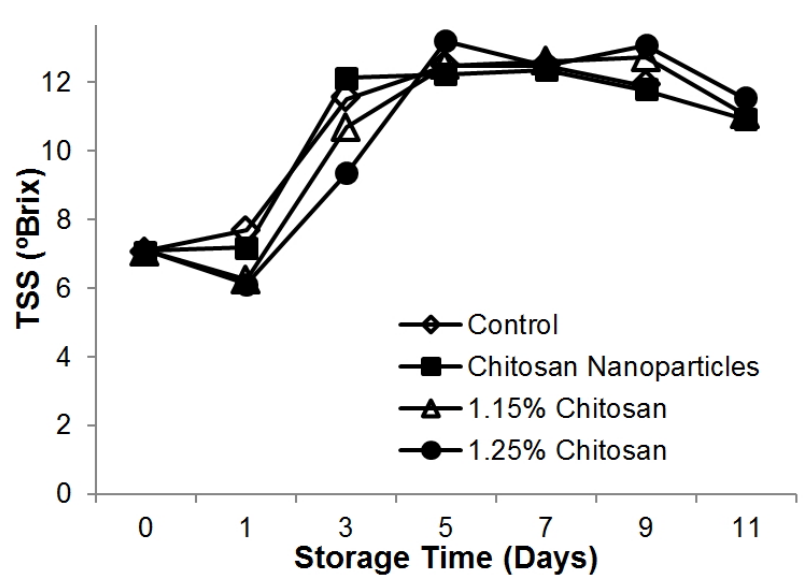

Fig. 6 Effect of Various Chitosan Coating Solutions on TSS of Banana Fruits During Storage at $25 \pm 1{ }^{\circ} \mathrm{C}$ for 11 days

banana. However, it can be clearly observed in Figure 5, TSS of banana increased on day 3. While, starch content of banana started to decrease on day 3 (Figure 3). This results indicated that there is a relation between the increase of TSS and the decrease of starch content. Most of the soluble solids content in ripe banana is sugar and during ripening, the starch of banana is converted to sugar so soluble solid content increases (Dadzie and Orchard 1997). At day 3, banana coated with CS $1.25 \%$ had the lowest TSS. This is due to the hydrolysis of banana pulp starch decreases as a result of reduction in banana metabolic process. It is inferred that an increase of chitosan concentration could increase thickness of coating, so that the diffusion of gases $\left(\mathrm{O}_{2}\right.$ and $\left.\mathrm{CO}_{2}\right)$ impeded due to the stomatal apertures of banana peel covered by coating. Coating can be a good barrier so that the oxygen content around the fruit decreases while $\mathrm{CO}_{2}$ increases, in addition it can also suppress the production of ethylene (Maqbool et al. 2011). The findings of Maqbool et al., 2011 support this result. They reported TSS on banana coated with chitosan rise slowly.

Scanning electron microscopy

The microstructures of the surface of control and coated banana peel with various of coatings (CN, CS $1.15 \%$ and CS 1.25\%) are shown in Figures 7. The structure of the control banana surface and its stomatal apertures was clear (Figure 7(A)). Whereas, the surface of $\mathrm{CN}$ coated banana was glossier as compared to uncoated banana (Figure 7(B)). CN mostly filled in the cracks on the banana peel. As clearly observed in Figure 7(C) and 7(D), SEM results of the fruits coated with CS $1.15 \%$ and CS $1.25 \%$ showed coatings completely covered the banana surface and blocked 


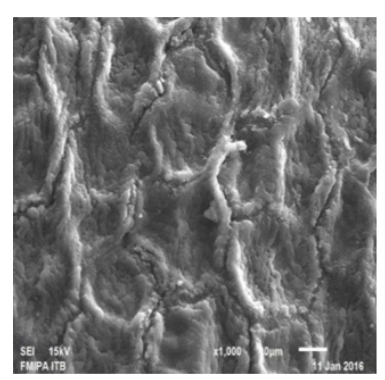

(A) Control

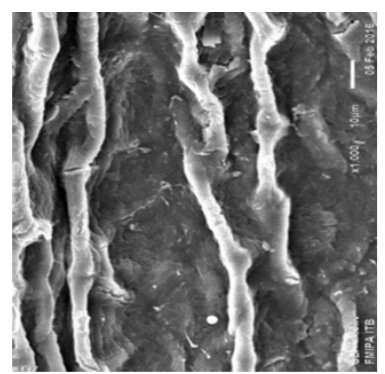

(C) $1.15 \%$ Chitosan

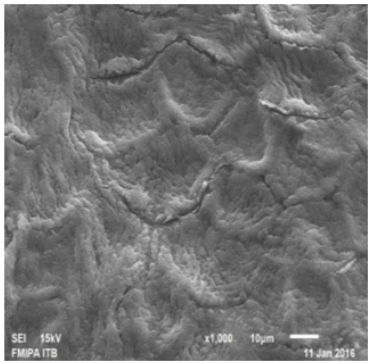

(B) Chitosan Nanoparticles

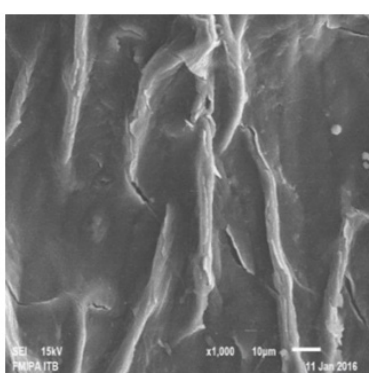

(D) $1.25 \%$ Chitosan
Fig. 7 SEM photographs of coated and uncoated banana fruits surface

the pores on the fruit surface. Coating banana fruit with $\mathrm{CN}$ and CS can retard the deterioration of banana fruits by modifying the internal atmosphere and reducing the respiration rate [Maqbool et al. 2011]. This resulted in less amounts of weight loss, TSS, pulp to peel ratio and extend the shelf-life of coated banana as compared to uncoated banana.

\section{Sensory evaluation}

Sensory evaluation of coated and uncoated banana fruits after six days of storage at $25 \pm 1^{\circ} \mathrm{C}$ period showed no significant $(\mathrm{P} \leq 0.05)$ differences on taste, colour and overall acceptability. It was indicating that either $\mathrm{CN}$ or CS did not effect the sensory quality of treated bananas (Table 2).

\section{Expression of $M A-A C S 1$ and $M A-A C O$}

The effect of chitosan coating on expression of MA-ACS1
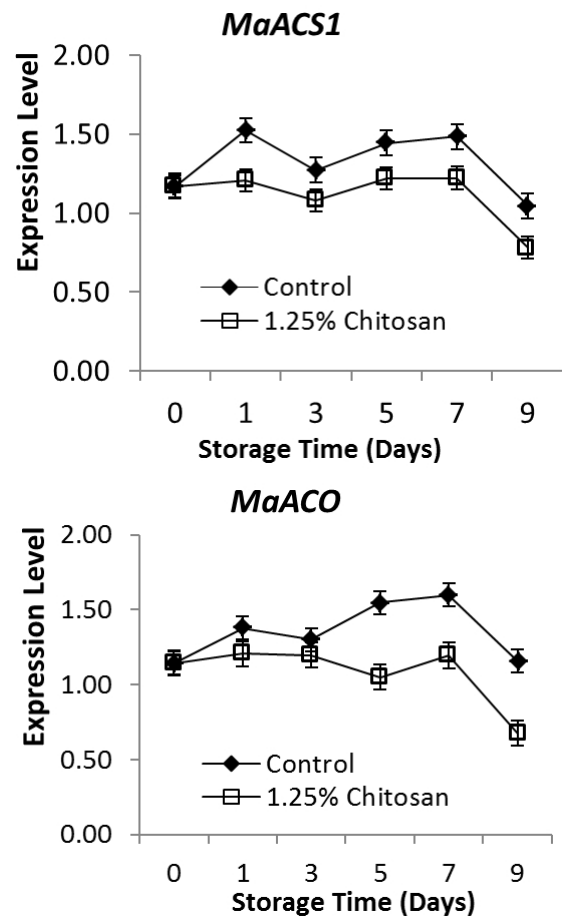

Fig. 8 Effect of Chitosan Coating on Expression Level of MaACS1 and MaACO of Banana Fruits During Storage at $25 \pm 1{ }^{\circ} \mathrm{C}$ for 9 days

and $M A-A C O$ of bananas are shown in Figure 8. The treated banana with $1.25 \% \mathrm{CS}$ had significant $(\mathrm{P} \leq 0.05)$ effect on expression of $M A-A C S 1$ and $M A-A C O$ of bananas as compared to uncoated banana. As clearly observed in Figure 8, The expression level of MaACS1 and MaACO of banana coated with $1.25 \%$ CS was lower than uncoated banana (control). This results indicated that $1.25 \% \mathrm{CS}$ provided a good barrier, so the production of ethylene decreased (Maqbool et al. 2011). Low level of ethylene production decreased maybe due to the reduction of $M A-A C S 1$ and $M A-A C O$ expression since ethylene regulate the expression of ripening related genes such as MA-ACSI and MA-ACO (Esyanti et al. 2013).

Based on results from this research, it was confirmed that Chitosan nanoparticles and chitosan can provided a good effects on postharvest quality of banana include shelf-life, starch content, weight loss, pulp to peel ratio,

Table 2 Sensory evaluation of coated banana after six days of storage at $25 \pm 1^{\circ} \mathrm{C}$

\begin{tabular}{lccc}
\hline \multicolumn{1}{c}{ Treatment } & Taste & Colour & Overall acceptability \\
\hline Control & $4.54 \pm 0.26^{\mathrm{a}}$ & $3.96 \pm 0.25^{\mathrm{a}}$ & $4.27 \pm 0.14^{\mathrm{a}}$ \\
Chitosan Nanoparticles & $4.70 \pm 0.49^{\mathrm{a}}$ & $3.66 \pm 0.39^{\mathrm{a}}$ & $3.67 \pm 0.32^{\mathrm{a}}$ \\
$1.15 \%$ Chitosan & $4.68 \pm 0.34^{\mathrm{a}}$ & $4.53 \pm 0.92^{\mathrm{a}}$ & $4.42 \pm 0.59^{\mathrm{a}}$ \\
$1.25 \%$ Chitosan & $4.84 \pm 0.24^{\mathrm{a}}$ & $4.47 \pm 0.24^{\mathrm{a}}$ & $4.42 \pm 0.32^{\mathrm{a}}$ \\
\hline
\end{tabular}

Mean values \pm standard deviation in the same column with a same letter are not significantly different 
TSS and sensory quality. The application of chitosan edible coating could extend the shelf-life of banana fruits up to several days. In general, the coated banana samples could delay ripening prosess so that it had lower weight loss, pulp to peel ratio and TSS values as compared to control samples. In addition, the coated banana could maintain the sensory quality. Molecular analysis showed that MaACS1 and $M a A C O$ gene expression of coated bananas was lower than control. This study could be considered as one of the techniques to extend the shelf life of banana by retarding ripening process.

\section{Aknowledgements}

This study was funded by Hibah Kompetensi RISETDIKTI from Ministry of Higher Education and Research Indonesia 2016 for Fenny Dwivany. The authors also thank PT. Sewu Segar Nusantara for fruit materials support.

\section{References}

Ahmad S, Thompson, AK, Asi AA, Mahmood Khan, Chatha GM, Shahid MA (2001) Effect of Reduced $\mathrm{O}_{2}$ and Increased $\mathrm{CO}_{2}$ (Controlled Atmosphere Storage) On The Ripening and Quality of Ethylene Treated Banana Fruit. International Journal of Agriculture \& Biology Vol. 3 No. 4

Avadi MR, Sadeghi AMM, Mohammadpour N, Abedin S, Atyabi F, Dinarvand R, Tehrani MR (2010) Preparation and Characterization of Insulin Nanoparticles Using Chitosan and Arabic Gum with Ionic Gelation Method. Nanomedicine: Nanotechnology, Biology, and Medicine 6:58-63

Blankenship, SM, Ellsworth DD, Powell RL (1993) A Ripening Index for Banana Fruit Based on Starch Content. HortTechnology 3(3):338-339

Bhumkar DR, Pokharkar VB (2006) Studies on Effect of pH on Cross-linking of Chitosan With Sodium Tripolyphosphate: A Technical Note. AAPS PharmSciTech 7 (2) Article 50

Burg SP, Burg EA (1962) Role of ethylene in fruit ripening. Plant Physiology 37:179-189.

Cano MP, De Ancos B, Matallana C, Camara M, Reglero G, Tabera J (1997) Difference Among Spanish and Latin-American Banana Caltivers: Morphological, Chemical and Sensory Characteristics. Food Chemistry 59 (3):411-419

Chien P, Lin H, Su M (2013) Effects of Edible Micronized Chitosan Coating on Quality and Shelf Life of Sliced Papaya. Food and Nutrition Sciences 4:9-13

Chien P, Sheu F, Yang F (2007) Effects of Edible Chitosan Coating on Quality and Shelf Life of Sliced Mango Fruit. Journal of Food Engineering 78:225-229

Corderio MCR, Silva MS, Oliveira-Filho EC de (2008) Optimization of a Method of Total RNA Extraction from Brazilian Native
Plants Rich in Polyphenols and Polysaccharides. Brasilia

Dadzie BK, Orchard JE (1997) Routine Post Harvest Screening of Banana/Plantain Hybrids : Criteria and Methods. INIBAP Technical Guidelines 2 International Plant Genetic Resources Institute (Rome, Italy)

Dong H, Cheng L, Tan J, Zheng K, Jiang Y (2004) Effects Of Chitosan Coating on Quality And Shelf Life of Peeled Litchi Fruit. Journal of Food Engineering 64:355-358

Dwivany FM, Hermawaty D. and Esyanti RR (2016) 'Raja Bulu' banana MaACS1 and MaACO1 gene expression during postharvest storage. Acta Horticullturae (ISHS) 1120:111-114

Eshghi S, Hashemi M, Mohammadi A, Badii F, Mohammadhoseini Z, Ahmad K (2014) Effect of Nanochitosan-Based Coating With and Without Copper Loaded on Physicochemical and Bioactive Components of Fresh Strawberry Fruit (Fragaria x ananassa Duchesne) During Storage. Food Bioprocess Technology 7:2397-2409

Esyanti RR, Dwivany FM, Latief C, Handayani RU, Swandjaja LWP, Ginaldi A (2012) Ground Based Study of The Effect of Open And Close Chamber Condition on Banana Ripening Process. A Journal of Life Sciences Vol 2 No 2

Fan, Wen, Yan, Wei, Xu Zushun (2012) Formation mechanism of monodisperse, low molecular weight chitosan nanoparticles by ionic gelation technique. Colloids and Surfaces B: Biointerfaces 90:21-27

Gan G, Wang T, Cochrane C, McCarron P (2005) Modulation of surface charge, particle size and morphological properties of chitosan-TPP nanoparticles intended for gene delivery Colloids and Surfaces B: Biointerfaces 44: 65-73

Jianglian, Duan, Zhang S (2013) Application of Chitosan Based Coating in Fruit and Vegetable Preservation: A Review. Journal of Food Processing \& Technology 4:5

Jiang Y, Li Y (2001) Effect of Chitosan Coating on Postharvest Life and Quality of Longan Fruit. Food Chemistry 73:139-143

Jonassen H, Kjøniksen AL, Hiorth M (2012) Effects of Ionic Strength on The Size and Compactness of Chitosan Nanoparticles. Colloid and Polymer Science 290:919-929

Karikari SK, Marriott J, Hutchins P (1979) Changes During The Respiratory Climacteric in Ripening Plantain Fruits. Scientia Horticulturae 10:369-376

Karmawan LU, Suhandono S, Dwivany FM (2009) Isolation of MA-ACS Gene Family and Expression Study of MA-ACS1 Gene in Musa acuminata cultivar Pisang Ambon Lumut. Journal Hayati of Bioscience 16(1):35-39

Ke D, Kader A (1989) Tolerance and Responses of Fresh Fruits to Oxygen Levels at or Below 1\%. In: J.K. Fellman (ed.) Proceeding of Fifth International Controlled Atmosphere Research Conference Vol 2

Kudachikar VB, Kulkarni SG, Keshava Prakash MN (2011) Effect of Modified Atmosphere Packaging On Quality and Shelf Life of 'Robusta' Banana (Musa sp.) Stored at Low Temperature. Journal of Food Science and Technology 48(3):319324

Li M, Slaughter DCT, Thompson JF (1997) Optical Chlorophyll Sensing System for Banana Ripening. Postharvest Biology 
and Technology 12:273-283

Luo Y, Wang Q (2013) Recent Advances of Chitosan and Its Derivatives for Novel Applications in Food Science. Journal of Food Processing \& Beverages 1(1):13

Mao S, Wei S, Thomas K (2010) Chitosan-based Formulations For Delivery of DNA and siRNA. Advanced Drug Delivery Review 62:12-27

Maqbool M, Ali A, Alderson PG, Zahid N, Siddiqui Y (2011) Effect of a Novel Edible Composite Coating Based on Gum Arabic and Chitosan on Biochemical and Physiological Responses of Banana Fruits during Cold Storage. Journal of Agricultural and Food Chemistry 59:5474-5482

Moura MR, Aouada FA, Avena-Bustillos RJ, McHugh TH, Krochta JM, Mattoso LHC (2009) Improved barrier and mechanical properties of novel hydroxypropyl methylcellulose edible films with chitosan/tripolyphosphatenanoparticles. Journal of Food Engineering 92:448-453
Park JH, Weller CL, Vergano PJ, Testin RF (1993) Permeability and Mechanical Properties of Cellulose-Based Edible Films. Journal of Food Science 58:1361-1364

Qi L, Xu Z, Jiang X, Hu C, Zou X (2004) Preparation and Antibacterial Activity of Chitosan Nanoparticles. Carbohydrate Research 339:2693-2700

Pratiwi A, Dwivany FM, Larasati D, Islamia HC, Martien R (2015) Effect of Chitosan Coating and Bamboo FSC (Fruit Storage Chamber) to Expand Banana Shelf Life. AIP Conference Proceedings 1677100005

Sarkar SD, Farrugia BL, Dargavill TR, Dhara S (2013) Physico-Chemical/Biological Properties of Tripolyphosphate Cross-Linked Chitosan Based Nanofibers. Materials Science and Engineering C 33 1446-1454

Sorrentino A, Gorassi G, Vittoria V (2007) Potential Perspectives of Bio-Nanocomposites for Food Packaging Applications. Trends in Food Science \& Technology 18:84-95 